\title{
Usos del territorio, acumulación por desposesión y derecho a la salud en la Argentina: el caso del cultivo de Tabaco Burley en la provincia de Misiones
}

\author{
Uses of territory, accumulation by dispossession and the right \\ to health in Argentina: the case of the cultivation of Burley \\ Tobacco in the province of Misiones
}

\begin{abstract}
Sebastián Gómez-Lende Universidad Nacional del Centro de la Provincia de Buenos Aires, Argentina
\end{abstract}

http://dx.doi.org/10.15359/rgac.60-1.5

\section{RESUMEN}

En el período histórico actual, la vulneración y el avasallamiento de los derechos humanos básicos se han erigido en la última frontera del capitalismo. Como resultado, los usos modernos del territorio suelen ser irracionales para la mayor parte de la sociedad, convirtiéndose en formas de acumulación por desposesión que a menudo representan una amenaza directa para la salud pública. En este trabajo, se procura demostrar que el cultivo de tabaco Burley en la provincia de Misiones opera, bajo la égida de la agricultura contractual, como un modelo que inequívocamente contribuye a la desposesión del derecho a la salud del campesinado local. Se analizan para ello los principales rasgos del modelo tabacalero misionero, las diversas formas de despojo implementadas por las empresas transnacionales en perjuicio de las familias agricultoras, las implicancias socio-sanitarias derivadas del uso intensivo de agrotóxicos y el papel desempeñado por el Estado.

1 Doctor en Geografía. Investigador Adjunto del Consejo Nacional de Investigaciones Científicas y Técnicas (CONICET). Centro de Investigaciones Geográficas (CIG), Instituto de Geografía, Historia y Ciencias Sociales (IGEHCS), CONICET/UNPCBA. E-mail: gomezlen@fch.unicen.edu.ar 
Sebastián Gómez-Lende. Uses of territory, accumulation by dispossession and the right to health in Argentina: the case of the cultivation of Burley Tobacco in the province of Misiones

Palabras clave: uso del territorio; acumulación por despojo; salud pública; tabaco Burley; Misiones (Argentina).

\begin{abstract}
In the current historical period, the infringement and subjugation of basic human rights have arisen as the last frontier of capitalism. As a result, modern uses of territory are often irrational for most of the society, thus becoming forms of accumulation by dispossession, which represent a direct threat to public health. The purpose of this paper is to show that the cultivation of Burley tobacco in the province of Misiones operates, under the aegis of contract farming, as a model that clearly contributes to the dispossession of the right to health of the local peasantry. In order to fulfil this goal, this article analyzes the main features of the tobacco model, the different forms of dispossession implemented by transnational corporations to the detriment of family farmers, social and health implications of the intensive use of pesticides, and the role played by the state.
\end{abstract}

Keywords: use of territory; accumulation by dispossession; public health; Burley tobacco; Misiones (Argentina).

\title{
Introducción
}

En el período histórico actual, el avasallamiento de los derechos humanos básicos parece haberse erigido en la última frontera del capitalismo. El objetivo de este trabajo consiste en demostrar que el modelo tabacalero, actualmente vigente en la provincia de Misiones encarna un uso irracional del territorio para la mayor parte de la sociedad local, donde la agricultura contractual, impuesta por las empresas transnacionales del sector, opera como una forma de acumulación por despojo que vulnera el derecho a la salud del campesinado.

En primer término, se desarrolla una breve caracterización del área de estudio. Seguidamente, se presenta un escueto marco teórico-conceptual, donde se abordan las relaciones entre los usos del territorio, la acumulación por desposesión y la salud pública. A continuación, se analizan los principales rasgos del modelo tabacalero misionero, así como también las diversas formas de desposesión implementadas por las compañías tabacaleras en perjuicio de las familias agricultoras. El siguiente apartado, se encuentra enteramente dedicado a estudiar la relación existente entre el modelo tabacalero y el despojo del derecho a la salud de las familias campesinas; para ello, se analizan las graves implicancias socio-sanitarias derivadas del uso intensivo de agrotóxicos, el papel desempeñado por el Estado y las estrategias de las empresas. Finalmente, se presentan las conclusiones del trabajo. 

Argentina: el caso del cultivo de Tabaco Burley en la provincia de Misiones

\section{Área de estudio. Breve caracterización de la provincia de Misiones}

Situada en la llamada 'triple frontera', la provincia de Misiones limita al oeste con Paraguay, al este, norte y sur con Brasil, y al sudoeste con la provincia de Corrientes (Figura 1). Con una superficie de $29.801 \mathrm{~km} 2$, esta provincia se encuentra rodeada por los ríos Paraná, Uruguay, Iguazú, San Antonio y Pepirí Guazú. Su clima es subtropical húmedo sin estación seca. En cuanto a relieve y flora, Misiones se halla integrada geológica y ecológicamente al Macizo de Brasilia y la Selva Paranaense, respectivamente.

Originariamente habitada por pueblos aborígenes de la etnia mbya guaraní, Misiones fue uno de los principales bastiones de las reducciones jesuitas (1609-1767) desarrolladas en el marco de la conquista española. Su integración al actual territorio argentino fue tardía, iniciándose con la Guerra de la Triple Alianza (1865-1870) y culminando con el auge de las colonias agrarias (1877-1930). Su división político-territorial contempla 75 municipios agrupados en 17 departamentos: Apóstoles, Cainguás, Candelaria, Capital, Concepción, Eldorado, General Manuel Belgrano, Guaraní, Iguazú, Leandro N. Alem, Libertador General San Martín, Montecarlo, Oberá, San Ignacio, San Javier, San Pedro y 25 de Mayo. 
Sebastián Gómez-Lende. Uses of territory, accumulation by dispossession and the right to health in Argentina: the case of the cultivation of Burley Tobacco in the province of Misiones

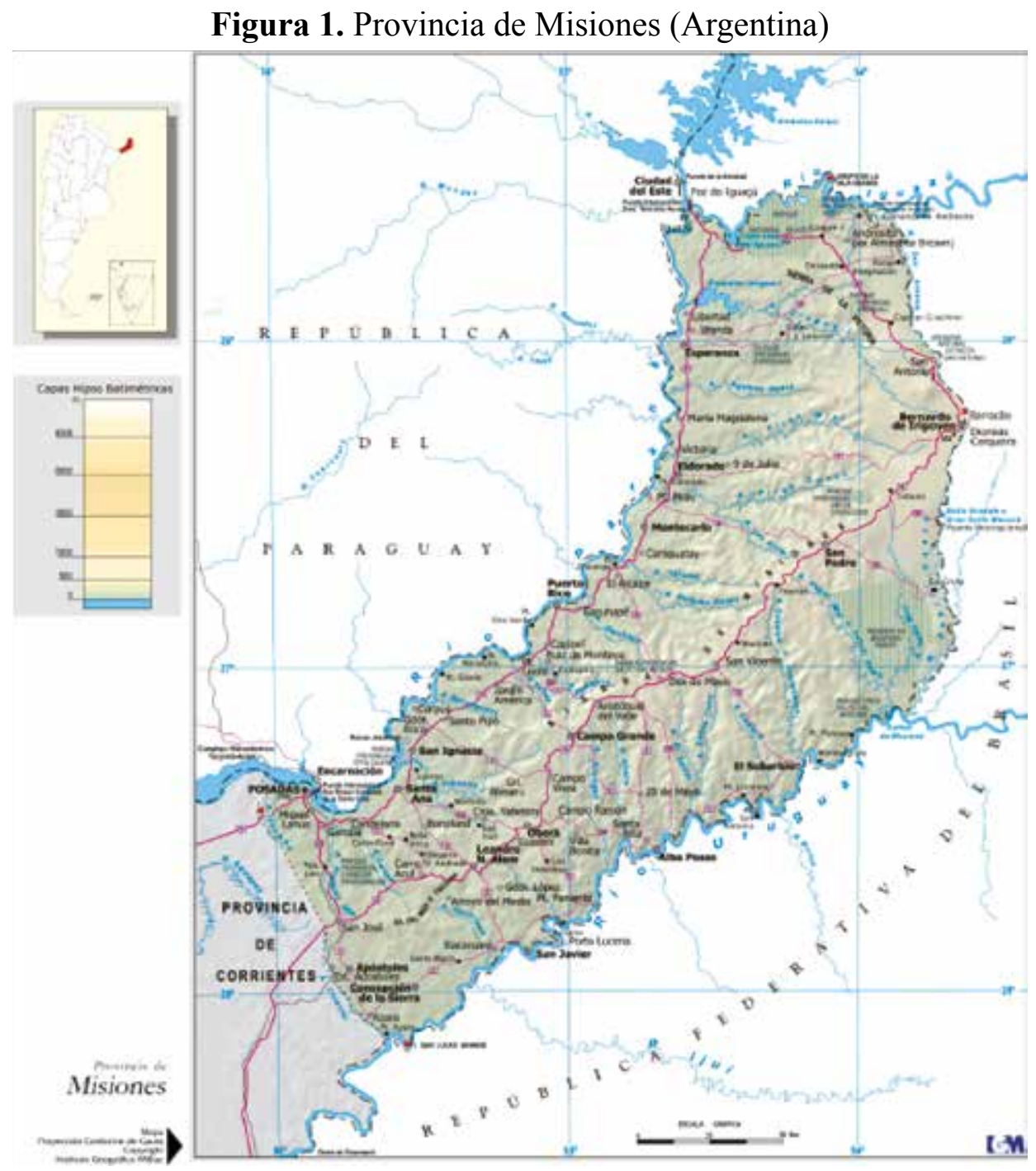

Fuente: IGN (sf).

La colonización agraria desarrollada entre 1877 y 1930 fue el principal factor histórico que moldeó la actual matriz económico-territorial de Misiones. La cesión gratuita de parcelas en tierras fiscales a inmigrantes brasileños, suizos, alemanes, austríacos rusos, polacos y ucranianos, determinó que la yerba mate $y$, en menor medida, el tabaco, se configuraran tanto en la fuente básica de ingresos monetarios para los colonos como en el motor 
de la ampliación de la frontera agrícola (Gallero, 2011; Slutzky, 2011). Esto sentó a su vez las bases de la estructura agraria, todavía vigente, caracterizada por el predominio del minifundio y la agricultura familiar campesina. Recién a mediados del Siglo XX, la estructura económica misionera alcanzó cierto nivel de diversificación, a raíz de la llegada de la industria forestal y la incorporación de cultivos como el tung, el té y los cítricos.

A partir de la década de 1990, la crisis estructural de los cítricos y, sobre todo, de la yerba mate, condujo a la reestructuración del clásico patrón agrario de capitalización, consolidando en su lugar a dos modelos productivos dominantes: las forestaciones exóticas a gran escala, integradas a la industria celulósico-maderera y la pequeña producción agrícola, estructurada en derredor del tabaco como principal cultivo de renta (García, 2011). A lo anterior, debe añadirse el notable auge ganado por el turismo durante las últimas décadas.

En 2010, la provincia contaba con 1.101.593 habitantes, en gran parte concentrados en la capital (Posadas). Su tasa de urbanización ascendía al 73,8\% (Argentina, 2013a). En la actualidad, Misiones es reconocida como una de las provincias más pobres de la Argentina. Según fuentes oficiales, en 2013, la pobreza alcanzaba al 9,7\% de los habitantes de Posadas, y la indigencia, al 2,4\% (Argentina, 2014). Estimaciones independientes, en cambio, situaban esos guarismos en el orden del $48,6 \%$ y el $21,7 \%$, respectivamente (IPPYP, 2014).

\section{Espacio geográfico, usos del territorio, acumulación por despo- sesión y salud pública}

Si el espacio geográfico es un conjunto solidario, indisociable y contradictorio de sistemas de objetos y sistemas de acciones mediados por normas, el territorio es ese mismo espacio explicado a partir de sus usos (Santos, 1996; Santos y Silveira, 2001). En el período histórico actual, los usos modernos del territorio operan en gran medida como formas de 'acumulación por desposesión', es decir, como modalidades de producción capitalista basadas en el saqueo, la depredación, el fraude, el despojo y/o la violencia (Harvey, 2004). Debido a que el avance de la acumulación por desposesión en la periferia del sistema garantiza la reproducción ampliada del capital en el centro (Amin, 1975), estas prácticas desempeñan un papel cada vez más crucial en la expansión del capitalismo (Harvey, 2004). 
Sebastián Gómez-Lende. Uses of territory, accumulation by dispossession and the right to health in Argentina: the case of the cultivation of Burley Tobacco in the province of Misiones

La acumulación por desposesión abarca diversos mecanismos, desde la continuidad de modalidades pretéritas o seculares de despojo -mercantilización y privatización de la tierra, desplazamiento de granjas familiares y expulsión forzosa de campesinos y aborígenes, privatizaciones, monetarización, crédito y usura, deuda nacional, esclavitud, etc.- hasta el surgimiento de dispositivos de expropiación más modernos y sofisticados -degradación del hábitat, transferencia de bienes ecológicos y servicios ambientales, determinados derechos de propiedad intelectual (patentes, licencias de material genético y plasma de semillas), biopiratería, pillaje de la reserva mundial de recursos genéticos, etc.- (Harvey, 2004).

So pretexto de modernidad, progreso e inserción en el mercado mundial, estos procesos suelen ser respaldados y promovidos por el propio Estado, que utiliza su monopolio en la definición de legalidad y el ejercicio de la violencia en contra de la voluntad popular (Harvey, 2004). Si la acumulación por desposesión es, en esencia, 'el saqueo y robo de los derechos de las personas' (Harvey, 2006), este despojo a menudo implica una amenaza para la salud pública. Santos y Silveira (2001) explican que los usos modernos del territorio suelen ser irracionales para la mayor parte de la sociedad, excepto para los agentes hegemónicos beneficiados por ese modelo de organización espacial. Esa irracionalidad se vuelve aún más descarnada cuando esos mismos usos del territorio suponen una amenaza para la salud de la población, atentando incluso contra la reproducción de la propia vida humana. La estrategia de los países ricos industrializados de externalizar los riesgos ecológicos y sanitarios de producir ciertos bienes a las naciones del Tercer Mundo, para luego importar esos mismos productos a buen precio (Beck, 1998), conduciría a una sutil y velada desposesión del derecho a la salud de la población en aquellos países periféricos, especializados en el desempeño de ciertas funciones de la división internacional del trabajo

Siguiendo a Beck (1998), en el sistema capitalista actual es cada vez más habitual que aquello que por un lado hace crecer la productividad por el otro acabe provocando enfermedades. En este sentido, parte del respaldo que los Estados de los países periféricos brindan a la acumulación por desposesión, consistiría en legitimar y naturalizar los riesgos ecológicosanitarios de ciertos usos hegemónicos del territorio. En el caso de los productos e insumos tóxicos, esa legitimación suele contemplar el establecimiento de valores límites de tolerancia para el uso de ciertas sustancias, 
imponiendo así una 'ración duradera de envenenamiento colectivo normalizado' (Beck, 1998). Otra función de la política consistiría en 'reparar' los 'daños colaterales' generados y, sobre todo, neutralizar las denuncias y presiones que pudieran afectar a los intereses económicos en juego.

Bajo la égida del actual modelo de agricultura industrial (o 'agro-negocio'), el uso intensivo de plaguicidas contribuye sustancialmente a ese envenenamiento colectivo normalizado. Según la Organización Mundial de la Salud (OMS), el número de intoxicaciones con agroquímicos se situó, entre la década de 1980 y comienzos del Siglo XXI, en el orden de los 3 millones de casos anuales, con un altísimo nivel de sub-registro ( 25 millones de casos no declarados) y una mortalidad de 220.000 personas/año; en las naciones del sur, la tasa era 13 veces mayor a la de los países industrializados (GRR, 2009). Cada año, la intoxicación aguda con plaguicidas afecta a tres de cada 100 trabajadores rurales en el mundo. El cuadro se agrava en los países en desarrollo, responsables por el $75 \%$ del consumo internacional de agrotóxicos; aquí, la desnutrición aumenta la vulnerabilidad de la población a los riesgos de la exposición laboral a estos productos (Argentina, 2007).

\section{Rasgos del modelo tabacalero misionero. Su papel en la acumu- lación por desposesión}

La internacionalización y transnacionalización de la industria cigarrera se remonta a la década de 1960, cuando factores como la saturación de la demanda, las campañas anti-tabaco, las restricciones impuestas a la publicidad y las presiones impositivas en los países industrializados, los crecientes costos de producción de materia prima en Estados Unidos y Europa, la necesidad de hallar nuevas fuentes baratas de tabaco en hoja, y la imposición del cigarrillo rubio americano (american blend) como patrón de consumo, reorientaron las inversiones de las compañías del sector hacia América Latina (Teubal, 1995). En la Argentina, el aumento de la concentración empresarial, la estrategia exportadora de British American Tobacco y Philip Morris, y la creación en 1972 del Fondo Especial del Tabaco (FET) como eje articulador de la política tabacalera nacional, alentaron, a partir de 1979, la difusión del tabaco Burley² en la provincia de Misiones (Teubal, 1995; Slutzky, 2011).

2 Se denomina Burley al tabaco 'curado al aire', con un mínimo control artificial de la humedad. Su contraparte es el tabaco Virginia, también denominado 'curado al cañón' (flue cured). 
Sebastián Gómez-Lende. Uses of territory, accumulation by dispossession and the right to health in Argentina: the case of the cultivation of Burley Tobacco in the province of Misiones

No obstante, el boom del Burley misionero recién se desató en 1989, cuando la apertura de nuevos mercados (Europa oriental, por ejemplo) reorientó la producción argentina casi por completo hacia la exportación. Las empresas transnacionales integradas al acopio y la exportación estrecharon su relación con el sector primario por la vía de los contratos agroindustriales -agricultura contractual o bajo contrato-, para así responder a los acuerdos suscritos con los grandes dealers internacionales, que exigían un abastecimiento regular en cantidad y calidad de las mezclas requeridas. Este cambio marcó, ciertamente, un punto de inflexión para el productor tabacalero misionero, que antaño solía vincularse con comerciantes que intermediaban en representación de los acopiadores (García, 2011).

En Misiones, el camino para la difusión de la agricultura contractual tabacalera fue allanado por la existencia previa de una agricultura campesina familiar de subsistencia, la condición oligopsónica del mercado de acopio, la caída de los precios de cultivos tradicionales (yerba, tung, té), y la inviabilidad para el campesinado de adoptar otras alternativas productivas, debido a sus altos costos y sus dilatados plazos de recuperación de la inversión. Otros factores, como la rápida aceptación en el mercado mundial del Burley misionero por su condición de producto artesanal, las aptitudes climáticas para su cultivo y la propaganda efectuada por los acopiadores respecto de su aparente rédito económico, hicieron el resto (García, 2011).

Como resultado, la superficie implantada con tabaco Burley en la provincia aumentó un 425,8\% entre 1986/87 y 2013/14 -pasó de 4.850 a 25.500 hectáreas-, en tanto que la producción creció un 485,8\% -pasó de 6.286.460 a 36.826.527 kilogramos- (Argentina, 2015). En toda la provincia existen aproximadamente 12.000 explotaciones tabacaleras, mayoritariamente concentradas en los departamentos de Guaraní, 25 de Mayo, Leandro N. Alem y Cainguás; el $96,6 \%$ de esas unidades posee una superficie inferior a las 10 hectáreas, y el 52,7\%, menor a las 2 hectáreas (Argentina, 2005; 2006). Organizador y centralizador de la vida del campesinado, el tabaco exige la participación de todo el grupo familiar en el proceso de producción; la extensión del calendario agrícola (330 días), la escasa o nula capacidad de ahorro y capitalización del productor, los cuidados intensivos que requiere el cultivo y su condición que éste detenta como única fuente de renta, implican que no sólo el jefe de familia, sino 
también su mujer e hijos de diferentes edades, intervengan obligada y cotidianamente en el cultivo de tabaco (Souza Casadinho, 2013).

La agricultura contractual tabacalera constituye, de principio a fin, una cadena de acumulación por desposesión. Cuando el campesino suscribe un contrato de producción con el acopiador al inicio de cada campaña tabacalera, se compromete a satisfacer (en el plazo pautado) el cupo asignado en cuanto a volumen y calidad de materia prima, aceptar la supervisión técnica de la empresa, utilizar los insumos proporcionados por esta última, y no comercializar la producción por fuera de los canales establecidos por el acopiador (García, 2011). Esto no sólo obliga al campesino a operar con un limitado margen de autonomía, sino que permite a las tabacaleras extranjeras controlar indirectamente el proceso productivo, externalizar riesgos, imponer condiciones específicas de cultivo y calidad, y extraer plusvalía al productor, apropiándose de la renta del suelo y del valor del trabajo familiar (Slutzky, 2011). Las empresas lucran así tanto con el precio del acopio pagado en relación al precio de exportación -y/o el precio del cigarrillo- como con la deuda del productor en concepto de insumos adelantados, financiamiento y asesoramiento técnico.

Durante la década de 1990, Philip Morris y Universal Carolina Leaf se valieron de la naturaleza oligopsónica del mercado para imponer sus nuevos paquetes tecnológicos (básicamente, semillas y agrotóxicos) al campesinado misionero. Si bien el acopio local es integrado por seis empresas, las numerosas relaciones intra-firma existentes ${ }^{3}$ determinan que apenas tres -Philip Morris, Universal Carolina Leaf y Alliance One- comercialicen la totalidad de las cosechas (García, 2011). Los altos niveles de concentración empresarial en el eslabón acopiador e industrial indujeron a los agricultores a adquirir esos paquetes tecnológicos so pena de, en caso contrario, no hallar compradores para su producción.

El campesino opera con un elevado margen de incertidumbre. Los contratos agroindustriales nunca estipulan cuál será el precio final del kilogramo de hoja de tabaco; a su vez, cuando el productor entrega su cosecha al acopiador, éste le abona el valor su producción en pesos, pero le descuenta

3 Estas empresas son: Cooperativa Tabacalera de Misiones (CTM); Comercial Industria Misionera Argentina (CIMA); Cooperativa Tabacalera de San Vicente (CTSV); Tabacos Norte (TN); Bonpland Leaf (BLASA); y Alliance One (AO). Cinco de esas seis razones sociales se hallan estrechamente relacionadas: CTM controla a CIMA y BLASA, y posee como clientes a AO y Massalin Particulares (MP), filial argentina de Philip Morris. AO, MP y BLASA -filial de Universal Carolina Leaf- participan de la explotación de TN (García, 2011). 
los costos financieros implicados en el capital adelantado y el precio de los insumos anticipados en dólares, conforme a la fluctuación del tipo de cambio $^{4}$ y la evolución del mercado mundial de agroquímicos (García, 2011). Obligados a entregar su producción 'a cuenta' -suelen transcurrir de diez días a tres meses entre el acopio y la fecha de pago-, los campesinos sufren otra sustancial merma de su rentabilidad debido la segmentación del mercado del Burley en doce categorías, calidades y precios; así pues, el mejor precio corresponde a la categoría 'A', pero el grueso de las cosechas suele ser pagado como calidad 'B' o 'C' (Agüero, 2009; TD, 2010).

Otra forma de despojo, atañe al rechazo en las bocas de acopio de la producción obtenida con 'semillas caseras' importadas desde Brasil, así como también a la penalización de los agricultores que, atraídos por la diferencia cambiaria y los precios más elevados -en 2008, 9,00 pesos $/ \mathrm{kg}$ contra $\$ 5,75$ pesos $/ \mathrm{kg}$-, remesan hoja de tabaco al vecino país. Orientadas tanto a reforzar su posición oligopsónica en el mercado como a disciplinar al campesinado, las empresas prohíben estas prácticas y estigmatizan a quienes infringen la norma, sindicándolos como 'malos productores' y excluyéndolos del circuito (García, 2011).

El propio Estado nacional respalda y legitima ese proceso de acumulación por desposesión. El sector tabacalero aporta 2.000 millones de dólares anuales al fisco, esto es, el 4\% de la recaudación tributaria nacional (Corradini et al, 2005). En ese sentido, el Fondo Especial del Tabaco (FET) utiliza una parte de los impuestos extraídos al consumidor final para otorgar a los productores sobre-precios y adicionales de emergencia que complementan el precio de acopio. Sin embargo, esto funciona como un generoso subsidio encubierto para las tabacaleras, a la vez que inocula en el imaginario colectivo del campesinado la falsa creencia de que el tabaco es una alternativa rentable. La provincia de Misiones sólo percibe, de hecho, entre 30 y 40 millones de los 200 o 300 millones de pesos que, en teoría, debiera recibir del FET cada año (Agüero, 2009). Los campesinos sufren, asimismo, importantes demoras en la remesa de esos recursos, los cuales representan el único (y exiguo) margen de ganancia que la mayoría de los productores obtiene por el producto anual de su trabajo.

4 Luego de una década (1991-2001) de paridad nominal (fijada por ley) entre el peso argentino y el dólar estadounidense, la devaluación de la moneda nacional condujo a sensibles modificaciones del tipo de cambio: entre 2002 y 2008 , el valor del dólar fluctuó entre 3 y 5 pesos; en la actualidad (2015), alcanza los 10 pesos. 
El tabaco Burley es, para las empresas, un lucrativo negocio de exportación; de hecho, en Misiones constituye el tercer complejo exportador provincial (en 2012, 17,6\% del total), después de la celulosa y el té (Argentina, 2013c). Orientadas a Europa -Bélgica, Alemania, Holanda, Francia, Inglaterra, Rusia, Portugal-, China y América del Norte -Estados Unidos, Canadá-, esas remesas son, asimismo, alentadas por el propio Estado nacional, que beneficia a las firmas tabacaleras con el reparto discrecional de recursos públicos -reintegro de las retenciones o derechos de exportación, otorgamiento de subsidios directos- (García, 2011).

Sin embargo, el tabaco sólo deja al campesinado un saldo de vulnerabilidad, pobreza y miseria. Si bien los precios del Burley se cuadruplicaron entre 1992 y 2011 (Argentina, 2013b), la plusvalía obtenida por las empresas a expensas del agricultor no hace sino aumentar. En pleno boom exportador, la relación entre el precio recibido por el productor y el valor de exportación cayó del 80\% registrado en 1997-2001 al 61,5\% verificado en 2006-2009 (Slutzky, 2011). A razón de una media de seis personas por familia tabacalera, cada individuo obtenía entre 200 y 500 pesos mensuales (TD, 2010), cifra irrisoria frente a los 80 millones de dólares de tabaco que Misiones exporta anualmente (Argentina, 2013c).

Lo anterior explica las míseras condiciones de vida de las familias campesinas, que residen -en alarmantes condiciones de hacinamiento y promiscuidad- en viviendas extremadamente precarias, construidas de madera y con piso de tierra, en su mayoría carentes de agua potable y servicios sanitarios -el $80 \%$ no posee baño y el $50 \%$ carece de energía eléctrica- (Agüero, 2009; Slutzky, 2011). Se registraban, asimismo, altas tasas de analfabetismo $(4,1 \%)$ y escolaridad primaria incompleta $(45,5 \%)$ (Argentina, 2006; De Fina, 2015).

Las iniciativas orientadas a reconvertir al campesinado hacia actividades económicas presuntamente más rentables (stevia, cebolla, esencias, caña de azúcar, granos, apicultura, avicultura, ganadería porcina, insumos agrícolas, etc.) han sido sistemática y deliberadamente saboteadas desde el propio Estado. Ciertamente, esto es funcional a los intereses espurios del Estado nacional -que no está dispuesto a renunciar al generoso caudal de recursos que le aporta el sector- y las compañías tabacaleras -cuya prosperidad depende estrechamente de la subordinación del campesinado a la agricultura bajo contrato-. 
Sebastián Gómez-Lende. Uses of territory, accumulation by dispossession and the right to health in Argentina: the case of the cultivation of Burley Tobacco in the province of Misiones

\section{Tabaco y agrotóxicos en la provincia de Misiones: el despojo del derecho a la salud}

Lo que Silveira (2003) llama 'quimificación de la agricultura' ha recrudecido en la Argentina durante las últimas décadas. El consumo de agrotóxicos en la Argentina aumentó un 858\% entre 1991 y 2012 -pasó de 39 millones a 335 millones de litros/año-, con un promedio de aplicación (12 lts/ha) que cuadruplica la media de los países desarrollados (REDUAS, 2013). Como resultado, el mercado agroquímico argentino reporta a las empresas del sector una facturación de 2.500 millones de dólares/año (Eleisegui, 2015).

Misiones no es una excepción a la regla. Orientados a satisfacer los intereses de firmas biotecnológicas -Monsanto, Syngenta, Du Pont, Bayery tabacaleras -Philip Morris y Universal Carolina Leaf Tobacco-, los contratos agroindustriales obligan a los campesinos a aplicar una vasta gama de agrotóxicos, desde herbicidas, insecticidas y funguicidas hasta acaricidas, nematicidas, fito-reguladores e inhibidores de brotes. Los agroquímicos más utilizados son el glifosato de amonio, el paraquat, el acefato, el clorpirifós, el imidacloprid, la cipermetrina y el thiamethoxan (González, 2007; Dutra, 2010; Gallo, 2010; Souza Casadinho, 2013)5. La aplicación de los plaguicidas es manual (mochila pulverizadora).

El uso intensivo y cotidiano de estos productos representa, en sí mismo, una situación de alto riesgo sanitario agravada, a su vez, por una miríada de factores. Sobresalen, entre otros, la adquisición de agroquímicos fraccionados y/o sin marbete, la mezcla de insecticidas y herbicidas sin diluir para potenciar su efecto y disminuir el tiempo de trabajo y los costos de producción, y el desconocimiento respecto de la toxicidad real de dichos agrotóxicos, sus principios activos y sus dosis adecuadas de aplicación. Asimismo, los campesinos rara vez utilizan equipos de protección completa (mamelucos o delantales impermeables) debido a las altas temperaturas reinantes en la provincia, factor que a su vez multiplica el riesgo de intoxicación al favorecer la absorción cutánea e inhalatoria de los

5 Otros plaguicidas utilizados son: carbaryl; sulfluramida; fipronil; clomazone; napropamida; trifluralina; pendimetalin; S-metolacloro; carbofuran; endosulfán; metamidofos; fenamifos; metomil; oxicloruro de cobre; mancozeb; deltametrina; carbendazin; epoxiconazole; metalaxil; zineb; diazinon; tiocarbamatos; metsulfuron metil; y alcoholes grasos (González, 2007; Dutra, 2010; Gallo, 2010; Souza Casadinho, 2013). Son, en su mayoría, fosfitos, piretroides y organo-fosforados de amplio espectro y alta peligrosidad muy cuestionados a nivel mundial. Recientemente, el glifosato fue clasificado por la OMS como "Probablemente cancerígeno para seres humanos", incluyéndolo en el mismo grupo (2A) que el PCB y el formaldehído. 
plaguicidas (González, 2007; Páez, 2009; Dutra, 2010; Souza Casadinho, 2013; Parrotta, 2014).

Otra variable que aumenta el nivel de exposición de la población rural a los efectos de los plaguicidas atañe a la acumulación y/o quema de los envases vacíos de agroquímicos. Si bien, la responsabilidad por la recolección, gestión y disposición final de esos residuos recae sobre los acopiadores, las empresas rara vez cumplen con esta obligación; los agricultores almacenan los envases en sus galpones durante años, o bien los entierran, los arrojan a cursos de agua o los incineran (TD, 2010). Como resultado, el suelo, el aire y el agua son rutinariamente contaminados con sustancias tóxicas -dioxinas y furanos- (González, 2007).

En la provincia de Misiones existe un fuerte nivel de sub-registro epidemiológico respecto de la ocurrencia de intoxicaciones accidentales con agroquímicos (González, 2007). No obstante, en un relevamiento desarrollado en los municipios tabacaleros de Aristóbulo del Valle, San Vicente y Colonia Aurora se reportó que el 65\% de los agricultores entrevistados manifestó sufrir problemas de salud ligados al uso de plaguicidas (Páez, 2009). En Colonia Aurora, entre 10 y 15 campesinos fallecen anualmente por cuadros de intoxicación aguda con agroquímicos utilizados en el cultivo de Burley (González, 2007).

En el relevamiento efectuado por Dutra (2010), empero, todos los colonos entrevistados niegan haberse intoxicado con plaguicidas, pese a haber sufrido reiterados malestares, dolores de cabeza y vómitos, inmediatamente, después de fumigar; incluso algunos productores sostienen la creencia de que el contacto prolongado con los agroquímicos generaría en sus organismos 'inmunidad' ante los efectos adversos de los mismos (González, 2007). Para Souza Casadinho (2013), esta negación del deterioro corporal y estas falaces relaciones causa-efecto son una estrategia de defensa psicológica de los campesinos para no asumir la dura verdad de que deben envenenarse para sobrevivir.

Otro resultado derivado de la exposición laboral y ambiental a plaguicidas ha sido la aparición de graves patologías entre las familias campesinas tabacaleras. Se han reportado, por ejemplo, numerosos casos de afecciones respiratorias severas, malformaciones cardíacas y renales congénitas, epilepsia, trastornos metabólicos y endocrinos, infertilidad masculina, abortos espontáneos, ceguera, parálisis cerebral, retraso madurativo y 
Sebastián Gómez-Lende. Uses of territory, accumulation by dispossession and the right to health in Argentina: the case of the cultivation of Burley Tobacco in the province of Misiones

psicomotor, microcefalia e hidrocefalia, discapacidad intelectual, síndrome de Down, fisura labio-palatina, mutaciones genéticas (teratogénesis), miastenia gravis, ictiosis, linfomas, leucemia y otros tipos de cáncer (TD, 2010; Parrotta, 2014; De Fina, 2015).

Según un estudio realizado en la localidad de Colonia Aurora, más de la mitad de los campesinos entrevistados señalaba que al menos un integrante de su familia padecía enfermedades directamente vinculadas a la exposición a agrotóxicos, tales como malformaciones congénitas, cáncer, náuseas, vómitos, alteraciones del sistema nervioso y problemas de visión (Páez, 2009). Al otro lado del muro, los 'efectos secundarios' de los agroquímicos se convierten -en términos de Beck (1998)- en voces, ojos, caras y lágrimas.

Ese fenómeno de despojo del derecho a la salud afecta sobre todo a la población infantil, debido a la alta incidencia y prevalencia de malformaciones, leucemia y cánceres con metástasis. En Misiones, 14 de cada 1.000 niños nacen afectados por malformaciones, frente a una media internacional de 0,5 casos cada mil nacidos vivos (Parrotta, 2014). Se han registrado casos de niños nacidos sin pulmones, sin ojos, con ausencia total o parcial de cerebro (anancefalia) o con ictiosis (Gómez Demaio, 2009; NM DD.HH., 2009; Souza Casadinho, 2013; De Fina, 2015). Otra grave malformación detectada es la mielomeningocele, una enfermedad ocasionada por la falla del cierre del tubo neuronal del sistema nervioso central; como resultado, el niño nace con la médula espinal abierta o expuesta, sufriendo parálisis de vejiga, intestino grueso y miembros inferiores, hidrocefalia e incontinencia urinaria y fecal. La rehabilitación del neonato puede requerir hasta veinte intervenciones quirúrgicas (Gómez Demaio, 2009). Según estadísticas del Hospital de Niños de Posadas, 5,4 de cada 1.000 misioneros nacen afectados por esta patología, cifra 50 veces más elevada que la reportada para la provincia por el Centro Latinoamericano de Registro de Malformaciones Congénitas (Gómez Demaio, 2009; NM DD.HH., 2009).

En la localidad de San Vicente, los niveles de discapacidad reportados en 2011 superaban en un 60\% la media provincial, con notoria incidencia de las familias tabacaleras (De Fina, 2015). En San Antonio, Piñalito Norte y Aurora, se informó un elevado número de infantes con discapacidades graves ligadas al uso de agrotóxicos (Parrotta, 2014). En la comuna 
tabacalera de Colonia Alicia, el retraso intelectual y psicomotor alcanzaba al 84\% de los niños relevados (Gómez Demaio, 2009; NM DD.HH., 2009; Parrotta, 2014). A raíz de la modificación del genoma, existe una elevada probabilidad de que estas malformaciones y discapacidades sean transmitidas a la futura descendencia de los afectados (TD, 2010). A lo anterior, se añade la incidencia de neoplasias entre la población infantil, superando ampliamente la prevalencia esperada para la provincia de Misiones (Gómez Demaio, 2009).

Es importante destacar la evidente correlación existente entre la incidencia de las patologías mencionadas, el cultivo de tabaco Burley y la exposición laboral y ambiental a agrotóxicos. Gran parte de las solicitudes de medicamentos oncológicos recibidas por el Ministerio de Salud de Misiones provienen del centro de la provincia -área tabacalera por excelencia- (González, 2007); de allí, procede también el 80\% de los pacientes atendidos por las clínicas privadas (De Fina, 2015). Un equipo médico del Hospital de Niños de Posadas comprobó que casi todos los neonatos afectados por mielomeningocele habían sido gestados en áreas tabacaleras sometidas a la aplicación masiva de agrotóxicos ${ }^{6}$ (NM DD.HH., 2009). La alta tasa provincial de mortalidad infantil $(16,6 \%)$ era aún más elevada en departamentos tabacaleros como General Belgrano (18,5\%) y 25 de Mayo (22,9 \%o) (Slutzky, 2011).

Esta situación coloca a los agricultores misioneros en una difícil y casi insoluble encrucijada. La incertidumbre en cuanto a lograr la entrega del volumen pautado por contrato, la falta de certezas en cuanto al precio final a obtener y el importante porcentaje retenido por los acopiadores por los sobrevaluados insumos adelantados, obligan a los campesinos a aplicar dosis cada vez más elevadas de agroquímicos. Paradójicamente, y frente a la ausencia de alternativas de reconversión más rentables, la grave situación socio-sanitaria de sus familias los somete cada vez más al yugo del tabaco. Los agricultores deben afrontar altos gastos de atención médica, realización de estudios, intervenciones quirúrgicas y adquisición de medicamentos e insumos sanitarios (Souza Casadinho, 2013; De Fina,

6 Debido a la naturaleza lipofílica e hidrofóbica de los agroquímicos, metaloides, metales pesados y otros productos tóxicos se acumulan en el tejido adiposo de los seres humanos expuestos. En el caso de madres en gestación y/o período de lactancia, los agrotóxicos se incorporan al genoma materno, ingresan a la placenta y son excretados en la leche. La falla del cierre del tubo neuronal suele producirse en etapas tempranas del embarazo, generalmente a los 28 días de gestación (Gómez Demaio, 2009). 
Sebastián Gómez-Lende. Uses of territory, accumulation by dispossession and the right to health in Argentina: the case of the cultivation of Burley Tobacco in the province of Misiones

2015). Sus exiguos recursos los condenan a continuar plantando tabaco, tanto para obtener un mínimo rédito económico con el cual solventar los crecientes gastos médicos del grupo familiar como para acceder a la cobertura proporcionada por las obras sociales del sector?.

El boom del Burley misionero representa, pues, un claro ejemplo empírico de la tesis de Beck (1998) donde la amenaza visible de la muerte por hambre prevalece ante la amenaza invisible de la muerte por intoxicación ligada a la aplicación masiva de agroquímicos. Esto es funcional al interés de las tabacaleras y el Estado por ocultar el impacto sanitario de la actividad; procurando evitar engrosar las estadísticas provinciales, en cuanto a malformaciones congénitas y mortalidad infantil. La Asociación de Plantadores de Tabaco de Misiones (APTM) deriva a los enfermos a clínicas privadas locales y a centros asistenciales de alta complejidad de Buenos Aires, quebrantando así la legislación vigente ${ }^{8}$ (Gómez Demaio, 2009). Otro factor de sub-registro epidemiológico concierne a los propios profesionales médicos que, amedrentados por las presiones ejercidas por los intereses políticos y económicos en juego, desisten de denunciar los casos de intoxicación aguda con plaguicidas y mortalidad infantil por uso de agrotóxicos (González, 2007; De Fina, 2015).

Orientado a proteger los intereses de las compañías tabacaleras, el gobierno provincial niega y/o desmonta todo nexo causal entre la desposesión del derecho a la salud, el cultivo de Burley y el uso intensivo de agrotóxicos. Si bien la etiología de todas las patologías citadas se halla inequívocamente relacionada con la exposición a plaguicidas, no existen estudios oficiales exhaustivos, o bien, los proyectos implementados culminan abruptamente, debido a la falta de apoyo político de las dependencias gubernamentales locales y las desinteligencias entre éstas y el Ministerio de Salud de la Nación (González, 2007).

Por añadidura, los actores políticos y la APTM suelen minimizar la gravedad de la problemática socio-sanitaria de los agricultores, o bien, la atribuyen a otros factores, como la consaguinidad de parejas, el alcoholismo y la anemia y escasez de ácido fólico en mujeres embarazadas

7 El costo de los tratamientos e insumos médicos para la hidrocefalia y la mielomeningocele es inasequible para los campesinos. El valor del botón gástrico -renovable cada 6 meses- asciende a 660 dólares; la válvula para la hidrocefalia, a 1.500 dólares; y el esfínter urinario artificial, a 10.000 dólares (Gómez Demaio, 2009; De Fina, 2015).

8 Una ley de salud provincial establece que todo malformado debe ingresar al Hospital de Niños de Posadas. 
(Parrotta, 2014). Como plantea Beck (1998); estos 'expertos' acallan las protestas, temores y críticas de la opinión pública tildándolas de 'irracionales', a la vez que procuran convertir a la percepción social del riesgo en un problema de desinformación.

El Estado exhibe así una actitud que oscila entre la desidia y el ocultamiento: por un lado, la llamada 'ley provincial de agrotóxicos' ${ }^{9}$ es sistemáticamente avasallada por las empresas transnacionales del sector químico y, sobre todo, tabacalero, cuyos contratos continúan exigiendo a los agricultores el uso de sus paquetes tecnológicos como condición sine qua non para adquirir su producción; por el otro, la Comisión Técnica del Tabaco de la Provincia de Misiones asevera que el uso de agrotóxicos se redujo un $86 \%$ entre 2001 y 2011 -de $8,50 \mathrm{~kg} / \mathrm{ha}$ a $1,17 \mathrm{~kg} / \mathrm{ha}-$ (COTTAPROM, 2012), a pesar de que tanto el número de plaguicidas utilizados como sus dosis de aplicación no hacen sino aumentar.

Si bien es cierto, que algunos de los insecticidas organo-fosforados más peligrosos, como el acefato y el clorpirifós han comenzado a ser paulatinamente sustituidos por productos neonicotinoides de última generación y menor toxicidad relativa como el imidacloprid y el thiamethoxan (Dutra, 2010), esto responde más a una estrategia de las tabacaleras por preservar ciertos mercados internacionales que a un genuino interés por la salud de los campesinos. Otrora, incluida en el paquete tecnológico que el agricultor obligatoriamente debía utilizar, la cipermetrina, por ejemplo, ha sido prohibida por las compañías tabacaleras, debido a la decisión de la Unión Europea de rechazar el tabaco contaminado con ese insecticida de alta capacidad residual; esto no impide a los acopiadores fomentar entre los agricultores el uso de herbicidas más agresivos y riesgosos, como el paraquat (González, 2007). El perverso doble juego de las transnacionales tabacaleras impone al campesinado condiciones contractuales cada vez más inestables y contradictorias. El agricultor debe utilizar un vasto acervo de agroquímicos, pero posteriormente, -como explica De Fina (2015)es penalizado con la no renovación del contrato (y refinanciación de su deuda), si el Burley analizado en las bocas de acopio presenta altos niveles de toxicidad residual.

9 Esta ley, vigente desde 1993, prohíbe la utilización de agroquímicos cuyo uso haya sido prohibido en su país de origen y/o sus perjuicios para la salud humana hayan sido demostrados en otros países. 
Sebastián Gómez-Lende. Uses of territory, accumulation by dispossession and the right to health in Argentina: the case of the cultivation of Burley Tobacco in the province of Misiones

No obstante, el conformismo, ceguera y complacencia del campesinado ante los objetivos de las empresas hegemónicas comienza a mutar -parafraseando a Santos (1996)- hacia una actitud de descubrimiento, contra-finalidad y revuelta ante el orden global. Es el caso de 144 familias tabacaleras de Leandro N. Alem, San Vicente y otras localidades misioneras, que, en 2011, entablaron una millonaria demanda judicial contra Monsanto, Bayer, Du Pont, Philip Morris y Universal Carolina Leaf Tobacco en los tribunales de New Castle y Delaware. Asesorados por estudios jurídicos nacionales y extranjeros, los agricultores reclaman por los perjuicios sanitarios ocasionados por la obligatoria adquisición, a las empresas denunciadas, de glifosato con bromuro de metilo (MOL, 2011; De Fina, 2015).

\section{Conclusiones}

Las relaciones entabladas entre las agroindustrias y el campesinado a menudo multiplican los mecanismos de extracción de excedentes -formas de acumulación por desposesión- que benefician a las primeras en detrimento del segundo. En la provincia de Misiones, el cultivo del tabaco Burley no es una excepción a esa regla; por el contrario, se trata de un uso hegemónico del territorio donde las empresas acopiadoras se valen de la agricultura bajo contrato, la condición oligopsónica del mercado y la vulnerabilidad socioeconómica de los campesinos para apropiarse del valor del trabajo familiar y de la renta exportadora. Cada una de las pautas y condiciones contractuales impuestas a los productores forja, de hecho, un nuevo eslabón en la histórica y cotidiana cadena de dominación, marginalidad, pobreza y miseria que ata a los campesinos a los intereses de las firmas transnacionales del sector.

Beck (1998) sostiene que la agricultura contemporánea se ha convertido en el reino de los venenos y que, por ese motivo, representa una amenaza para la salud pública. El caso de estudio elegido, ciertamente, corrobora esa tesis. Obligatorio, el uso intensivo de plaguicidas constituye tanto una fuente de lucro para las compañías tabacaleras -a través de los llamados 'paquetes tecnológicos'- como un mecanismo de vulneración y avasallamiento de la salud de la población rural. Existe, de hecho, una comprobada correlación entre el cultivo de tabaco Burley, la exposición laboral y ambiental a agrotóxicos y la incidencia de un sinnúmero de graves patologías entre el campesinado. La población infantil es la principal 
afectada por ciertos 'daños colaterales' del modelo, como las enfermedades cancerígenas y los nacimientos con malformaciones. Esta situación adquiere ribetes perversos, pues obliga a los agricultores a continuar plantando tabaco ya no sólo para subsistir, sino también para costear los onerosos insumos y prestaciones asistenciales que requiere el grupo familiar; en otras palabras, en esa desposesión del derecho a la salud reside un factor que refuerza el yugo del campesinado a la actividad responsable por su pauperización y deterioro sanitario.

Ora por acción, ora por omisión, el poder político respalda y legitima ese despojo. El Fondo Especial del Tabaco perpetúa la subordinación de los campesinos, subsidia las estrategias de acumulación empresariales y otorga al Estado nacional una sustancial masa de recursos fiscales. Y el gobierno provincial niega $\mathrm{y} / \mathrm{u}$ oculta, finalmente, todo nexo causal entre el modelo hegemónico y el avasallamiento del derecho a la salud de la población.

\section{Referencias}

Agüero, J. O. (2009). La cuestión social en Argentina. Los tabacaleros en Jujuy y Misiones.Buenos Aires: Dunken.

Amin, S. (1975). La acumulación a escala mundial: crítica a la teoría del subdesarrollo. Buenos Aires: Siglo XXI.

Centro de Estudios e Investigación Social Nelson Mandela (NM DD. HH.) (2009). Una tragedia colectiva, en plena marcha. Malformaciones por el uso de agroquímicos. Argentina, Resistencia: Centro de Estudios e Investigación Social Nelson Mandela.

Beck, U. (1998). La sociedad del riesgo. Hacia una nueva modernidad. Barcelona: Paidós.

Comisión Técnica de Tabaco de la Provincia de Misiones (COTTAPROM). (2012). Uso de agroquímicos en el cultivo de tabaco. Provincia de Misiones. Argentina, Posadas: Comisión Técnica de Tabaco de la Provincia de Misiones.

Corradini, E., Cuesta, R., Merello, P., Segesso, R., Giménez, M. L., Zilocchi, H., Molfesa, S. y Musco, J. M. (2005). Caracterización del sector productor tabacalero en la República Argentina. Buenos Aires: UCSMBA.

De Fina, M. (2015). Los venenos. Recuperado de http://www.mariodefina. com/cronicas/los-venenos 
Sebastián Gómez-Lende. Uses of territory, accumulation by dispossession and the right to health in Argentina: the case of the cultivation of Burley Tobacco in the province of Misiones

Dutra, R. (2010). Plantadores de tabaco y riesgos socioambientales de los métodos de utilización de plaguicidas en San Vicente (Misiones, Argentina). Porto de Galinhas-Recife-Pernambuco: REDISEC.

Eleisegui, P. (2015). Argentina envenenada: proliferan el cáncer y las malformaciones por el uso de químicos para producir alimentos. Recuperado de http://www.iprofesional.com/notas/212108-Argentina-envenenada-proliferan-el-cncer-y-las-malformaciones-por-eluso-de-qumicos-para-producir-alimentos

El territorio (TD). (30 de mayo de 2010). Las dos caras del tabaco con las que viven 12 mil productores. En Territorio Digital. Posadas, Argentina. Recuperado de http://www.territoriodigital.com/nota. aspx? $=2613023321024028$

Gallero, M. C. (2011). Tabacaleros y acopiadores en la colonización del Alto Paraná Misionero (1930-1946). En Mundo Agrario. 22,(11). Recuperado de http://www.scielo.org.ar/pdf/magr/v11n22/v11n22a04.pdf

Gallo, G. (2010). Agroquímicos. ¿Por qué los agroquímicos se transforman en tóxicos? Argentina, Trelew: Fundación Patagonia Tercer Milenio.

García, A. (2011). Adaptaciones frente a una relación asimétrica: agricultores familiares y agroindustrias en el nordeste de Misiones (Argentina). En Estudios Socioterritoriales. Revista de Geografia, 2011. (10), 41-64.

Gómez Demaio, H. (9 de junio de 2009). Agroquímicos: misioneros con retraso mental grave y malformaciones. El Paranaense. Argentina, Posadas. Recuperado de http://www.ecoportal.net/Temas-Especiales/Salud/agroquimicos_misioneros_con_retraso_mental_grave_y_malformaciones

González, C. O. (2007). "Región Mesopotámica, Provincia de Misiones”. La Problemática de los Agroquímicos y sus Envases, su Incidencia en la Salud de los Trabajadores, la Población Expuesta y el Ambiente. Estudio colaborativo multicéntrico. Buenos Aires: Ministerio de Salud de la Nación. (137-180).

Grupo de Reflexión Rural-Editorial del Nuevo Extremo (GRR). (2009). Pueblos fumigados. Los efectos de los plaguicidas en las regiones sojeras. Buenos Aires: Grupo de Reflexión Rural-Editorial del Nuevo Extremo.

Harvey, D. (2004). El nuevo imperialismo. Madrid: Akal. 
Harvey, D. (2006). El nuevo imperialismo. Entrevista. Recuperado de http:// www.sinpermiso.info/textos/el-nuevo-imperialismo-entrevista

Instituto Geográfico Nacional. (IGN). (s.f.). Mapas e información geográfica de la República Argentina. Buenos Aires: Instituto Geográfico Nacional. Instituto de Pensamiento y Políticas Públicas (IPPYP). (2014). 36,5\% de pobres y 12,1\% de indigentes: los números que el gobierno pretende ocultar. Buenos Aires: Instituto de Pensamiento y Políticas Públicas. Instituto Nacional de Estadística y Censos. (2014). Encuesta Permanente de Hogares. Medición de hogares y personas bajo las líneas de pobreza e indigencia según regiones y aglomerados urbanos. Serie histórica: primer semestre de 2003-primer semestre de 2012. Buenos Aires: Instituto Nacional de Estadística y Censos.

Instituto Nacional de Estadística y Censos. (2013a). Población urbana y rural por provincia. Total del país. Año 2010. Buenos Aires: Instituto Nacional de Estadística y Censos.

Instituto Nacional de Estadística y Censos. (2005). Censo Nacional Agropecuario 2002. Resultados definitivos por cultivos, provincias y departamentos. Buenos Aires: Instituto Nacional de Estadística y Censos.

Ministerio de Agricultura, Ganadería y Pesca de la Nación. (2015). Evolución de la producción primaria de tabaco (1986/87-213/14). Buenos Aires: Ministerio de Agricultura, Ganadería y Pesca de la Nación.

Ministerio de Agricultura, Ganadería y Pesca de la Nación. (2013b). Evolución del precio de tabaco en el acopio, en el importe que abona el FET $y$ en el total percibido por el productor (1991/92-2010/11). Buenos Aires: Ministerio de Agricultura, Ganadería y Pesca de la Nación.

Ministerio de Agricultura, Ganadería y Pesca de la Nación. (2006). Explotaciones agropecuarias tabacaleras en la Argentina. Caracterización en base al Censo Nacional Agropecuario 2002. Buenos Aires: Ministerio de Agricultura, Ganadería y Pesca de la Nación.

Ministerio de Economía y Finanzas Públicas. (2013c). Complejos exportadores provinciales. Informe anual 2012. Buenos Aires: Ministerio de Economía y Finanzas Públicas.

Ministerio de Salud de la Nación. (2007). La problemática de los agroquímicos y sus envases, su incidencia en la salud de los trabajadores, la población expuesta y el ambiente. Estudio colaborativo multicéntrico. Buenos Aires: Ministerio de Salud de la Nación. 
Sebastián Gómez-Lende. Uses of territory, accumulation by dispossession and the right to health in Argentina: the case of the cultivation of Burley Tobacco in the province of Misiones

Misiones On Line (MOL). (24 de julio de 2011). Salud. Misiones: 120 familias litigan contra fabricantes de agrotóxicos. En Misiones On Line. Posadas, Argentina. Recuperado de http://www.saludnews24. com.ar/noticias/salud/5465--misiones-120-familias-litigan-contrafabricantes-de-agrotoxicos.html

Páez, S. (2009). Uso de agrotóxicos en el cultivo de tabaco: sus consecuencias en los actores sociales y en el espacio geográfico de la zona centro de la Provincia de Misiones, Argentina. Recuperado de http://bloglemu.blogspot.com.ar/2009/05/uso-de-agrotoxicos-en-el-cultivo-de.html

Parrotta, M. (23 de febrero de 2014). Misiones: aislados y rodeados de veneno. En Territorio Digital. Posadas, Argentina. Recuperado de http:// www.territoriodigital.com/notaimpresa.aspx?c=7679560780822591

Red Universitaria de Ambiente y Salud (REDUAS)/ Red de Médicos de Pueblos Fumigados. (2013). El consumo de agrotóxicos em Argentina aumenta continuamente. Análisis de los datos del mercado de pesticidas en Argentina. Buenos Aires: Red Universitaria de Ambiente y Salud/Red de Médicos de Pueblos Fumigados.

Santos, M. (1996). A natureza do espaço. Técnica e tempo, razão e emoção. Brasil, São Paulo: Hucitec.

Santos, M. y Silveira, M. L. (2001). O Brasil. Território e sociedade no início do século XXI. Brasil, Rio de Janeiro-São Paulo: Record.

Silveira, M. L. (2003). Argentina: território y globalização. Brasil, São Paulo: Brasiliense.

Slutzky, D. (2011). Estructura social agraria y agroindustrial del nordeste de la Argentina: desde la incorporación a la economía nacional al actual subdesarrollo concentrador y excluyente. Buenos Aires: IADE.

Souza Casadinho, J. (2013). Utilización de agrotóxicos e impacto en la salud en la actividad hortícola y tabacalera. Un problema de salud pública. I Congreso Universitario de Salud Pública. Buenos Aires: Universidad Nacional de Buenos Aires.

Teubal, M. (1995). "El agribusiness y la transnacionalización de la agricultura latinoamericana”. Globalización y Expansión Agroindustrial: ¿Superación de la pobreza en América Latina? Buenos Aires: Corregidor. (81-105). 